\title{
Research on Male Dan in Chinese Peking Opera and Castrato in Italian Opera
}

\author{
Qunying Wang \\ College of Music, Shaoguan University, Shaoguan, 512000, China
}

Keywords: Peking opera, Opera, Male Dan, Castrato, Pharyngeal voice, Vocal music

\begin{abstract}
Chinese Peking opera and Italian opera are ancient musical art forms in the East and West, and the reason why they are long-standing is that they have extensive and profound cultural heritage and the deep historical heritage, more importantly; they both have a special form of artistic expression. Either the male Dan in Chinese Peking opera or castrato in Italian opera uses profound vocal skills and unique interpretation ways to demonstrate the uniqueness of "pharyngeal singing", and present the highest level of "Men singing female roles". This paper from the perspective of these two forms of artistic expression and special vocal interpretation of pharyngeal tone, studies their value in the field of art today.
\end{abstract}

\section{Introduction}

In Peking opera, there are division of roles, including five classes, "Sheng, Dan, Jing, Mo Chou"; in opera, there are division of part, including three parts, "treble, midrange and bass", with differential octave, six gears. Multiple classifications of two art forms are aimed to make artistic expression more delicate and interpretation of the role more vivid, giving the art itself unlimited appeal. Although in Peking opera and opera, "female Dan" and "Female voice" should be interpreted by a woman, but because of traditional feudal thought in China and the Europe that woman can only make playing and singing and dance, and cannot perform on the stage, so the unique interpretation form of male playing females is passed on spontaneously in China and Europe, and male Dan and castrato emerge.

\section{Male Dan in Chinese Peking opera}

Chinese classical aesthetics strives for the aesthetic realm of "between like and not like", allowing exaggerated, impressionistic and expressive components in artistic expression, and also because of the ancient Chinese feudal thought that men are superior to women, male Dan stays as a division of roles in Peking opera.

The times create heroes. We can say that the extension of male Dan establishes the foundation for the prosperity of Chinese Peking opera. In the 20th century, the rise of Chinese Peking opera "four famous Dan" led by Mei Lanang, symbolized the pinnacle of Peking opera career in China. As a Peking opera master, Mei Lanfang upgrades artistic expression and skills of male Dan to a new level, making breakthrough in terms of singing, chants, music, performance, costume and make-up, and forming the gorgeous and elegant Mei school. It is under his lead that a lot of talents of Dan role emerged, like Cheng Yanqiu, Xun Huisheng and "four small famous Dan", Zhang Junqiu, Li Shifang, Song Dezhu, Mao Shilai, glorifying Peking opera considerably, and making immortal contributions to promoting the development of Chinese Peking opera career.

\section{Tone quality of male Dan}

According to different physical signs of people, tone quality characteristics of each person are different. But Peking opera thinks that, features and methods of sounding may be shaped and changed on the basis of the original sound. Opera Dan roles will use a large number of falsettos people won't use in their daily lives. They are the most important sound shape factor in performance of Dan roles.

In fact, the falsetto is not nice, but in order to make it conform to vocal plastic arts requirements, male Dan must strength vocal tension during the interpretation of falsetto, keeping vocal cords half closed, so that the breach will be able to release from the local vocal chords, producing different 
vibration from that produced in usually singing. Male falsetto takes advantage of this point, making the original deep and wide vocal pronunciation thinner and brittler, which is the effect produced by the front closed vocal cords. During interpretation of falsetto, male voice noticeably becomes "resonant", and the most typical example is the "Sipingdiao", the uniqueness of which is that the mixture of male and female voices, typical two-yellow cavity system. The overall performance is line cavity soothing, more bass and midrange. Bass is very low and treble is very high. So when men once sing, it is necessary to show a deep and rich bass, but also exhibit a bright crisp treble, and the overall music style has strong coherence requirements, with music section immediately turning treble to bass, so technically male singers are required to show the free and ease state for the tone conversion.

So as said above, if tone quality of male Dan in Peking opera needs to be gorgeous and easy, the breath is the most important. During singing, the control of timbre, pitch, volume has to rely on the control of breath. Only to master the breath, you can make your voice loud and penetrating, fully demonstrating the content and artistic appeal of the melody. So it can be said that breath is the "basis of vocal music". Peking opera pays attention to the relationship between breath and character, cavity, air and manner, as it said that "singing, chanting and acting all depend on breath". This is the "form" of Peking opera. We must stand firmly and stably. Articulation in Peking opera also depends on breath support, such as when singing vowels, we must grasp the relationship between it and the resonance. Coordinated use of both can be called singing. Of course, consonants do not vibrate vocal cords, but also need enough breath support to break pronunciation obstacle. There is a saying in Peking opera, "extremely heavy articulation touches listeners automatically and easily". This is powerful aura performance that the breath vigor brings.

\section{Line-cavity of male Dan}

Male Dan art demonstrated by Mei Lanfang has an absolutely important role in the whole Peking opera system, because it sounds beautiful, fluent, graceful, and innocent cleaning up people's hearts, pure and flawless. This explains the falsetto part of male Dan of Mei School has high tone area, but it is clear and flawless, which is the technical requirements of male Dan's falsetto. Clear and pure falsetto is mainly manifested on the line cavity. Professionally line cavity is required to be slim, soft, with clear pronunciation, which is very difficult for men with wide vocal cords. It must go through a long-term solid basic training before they are successful. Line cavity of male Dan is not simply to pursue female voice, but to also have a certain artistic appeal in clear articulation, gorgeous falsetto at the same time, vividly imitating the breath of women in different environments, and different emotional changes, as Mei Lanfang said, "sharp and round echo, pure and clear, from word to affection, word and cavity taken into account. [1]". So the experts often remarked that male Dan of Mei School pays attention to "words with the singing", which means that the singing must to be subject to emotional story and characters. And based on this point, achieve clear articulation and a mellow and full tune. When singing is not bound to the pronunciation, and the pronunciation is not damaged when singing, then it reaches the basic requirements for articulation and singing of Mei Lanfang male Dan.

\section{Castrato in Italian opera}

\section{Male canto treble and castrato}

In Europe there is no male treble initially, because only women treble is more sonorous and penetrating, which is the difference due to the physical structures of men and women. However, before the 16th century, the religion prohibited women to make a sound in the church, and because many choirs often performed in the church, so Roman pope prohibited women to sing on stage and polyphonic portion of choir in the church would be completed by boys instead of women. But boys would eventually experience mutation period, so the art form of male treble emerged, and the castrato was followed. Before puberty boys would undergo castration surgery to curb the development of vocal cords, thereby maintaining the male treble. 


\section{Falsetto technique of modern castrato}

In modern times, the castrato maintains the treble not through surgery to change physiology, but reasonable vocal practice methods to reach the effect of "men singing women", also called countertenor, "alto" in Italian. It is a type of sound in vocal music profession. Countertenor has a special method for vocalization, in general using a method call "light enginery", vibrating the edge of vocal cords to emit near-girls male treble with elegant feel. Although the main part of countertenor is still male voice, but it is with the help of strong breath that women do not have. Through repeated practice, we can achieve head chamber and vocal resonance similar to women's. Scientifically speaking, countertenor can reach all voice range women can achieve. That is the treble practice method using the combination of breath and vocal cords vibrations, so as to achieve the same singing effect of the castrato.

\section{Common points of male Dan in Peking opera and castrato}

Male Dan in Peking opera and castrato were born in the feudal society for special needs. The emergences of these two art forms have no any junction, but they share many similarities.

First, both emerged under the spirit imprisonment and physical oppression ruled by the feudal society monarchy. Either in medieval Europe or in pre-Qin and Han, Wei in China, they both emerged due to social form of "man is superior to woman" and adventurous psychology to please the imperial nobility, and they are special products under the feudal ethics abnormal social background; secondly, two forms are interpretation of the female voice by men. They need to go through a painful journey to create artistic achievements; and thirdly, the two art forms have their own peak. The 17th and 18th centuries in Europe are "Golden Age" of castrato. In the popular times of Italian opera and canto school, many great composers such as Mozart were willing to create tailored opera for castrato, such as the most prestigious "Don Juan". The castrato also pioneered coloratura technique of the canto art. By the 18th century, along with the coloratura technique castrato reached the top, creating countless brilliance. In the early 20th century in China, after over 200-year development of male Dan in Peking opera, vocal music school represented by "four famous Dan" pushed the peak of Peking opera, but also in this period, created countless well-known female characters. It also allows later generations think, the artistic value produced by "four famous Dan" is unprecedented, and incomparable; and fourthly, they have many similarities about the singing skills, for example, they both need a strong breath and cut-through resonance, but the most important thing is pharyngeal tone. Pharyngeal tone theory firstly emerged in Europe, and until after the 20th century it came into China. Although vocal method of male Dan does not use the pure pharyngeal tone skills, but after a study it was found that there are many similarities between many vocal techniques of male Dan and pharyngeal tone. For example, vocalization of male Dan stresses breathing into the belly, with small air displacement and small-open mouth, which is similar to breath holding practice of pharyngeal tone. Both use sound wave vibration of hard palate and oral cavity and increase singing intonation and charm through nasal cavity closure. Strictly speaking, voices of the male Dan and castrato are not falsetto, but voice between the genuine and fake sound, they rely on the palate lift to fix throat, and then use the breath sinking to cut through the sound from the chest to head to form resonance, which is the common point of castrato and male Dan in terms of singing techniques [2].

\section{Pharyngeal tone}

\section{Concept}

Pharyngeal tone came from Italy, and it experienced a great 18th century accompanied by the castrato. In Italian, "pharyngeal tone" is the "Voce faringea", able to be literally translated as "the voice of the pharyngeal". Vocal method of pharyngeal tone is scientific. In 1947, the Italian vocal music theorist Caesari initially published the particular method of singing of pharyngeal tone through his book "scientific sense of sound". The reason why pharyngeal tone is so attractive is that it breaks the limit of human sex, showing a new level of singing realm humanity can achieve. And this 
breakthrough is also the reason why male Dan in Peking opera and castrato in opera are able to usher in the peak. So for the modern art of music, the pharyngeal tone techniques should be passed on. Sounding theory it provides has a great reference value, and has a positive effect on promoting the development of vocal music [3].

\section{Practice method of pharyngeal tone}

The main method to practice pharyngeal tone is silent exercise, which is that the mouth does not sound. This practice method requires the practitioner to always relax the lower jaw, and not deliberately to press the chin, but to bend forward the head, and inhale in a relaxed state of the whole body. When looking up, also open the mouth. The beginners are likely because of such vocal exercises to have stiff chin and mouth not able to be opened; leading to that the sound cannot be vocalized smoothly. So they should firstly exercise to relax the jaw, do continuous repetitive silent practice, to ensure they can freely control their own lower jaws when in the vocal performance, and even forget its existence.

Secondly, strengthen the coordination of tongue and lower jaw, able to shake randomly the lower jaw and tongue, and freely produce voice, so it can make the stiff jaw and tongue relax, and help later vocal exercise.

Thirdly, pharyngeal tone practice focuses on deep breathing exercise. Practitioners should firstly stand stably and then slowly inhale, until the chest is filled with breath and hold this contour state of fully-filled chest, then exhale and inhale to exercise the power of the diaphragm and abdominal muscles, and each group of actions ends with no breath support. This muscle exercise should adhere to at least three minutes each time for one breath, and the action should gradually accelerate. Long practice will form a stable breathing action, and free use of breath.

The fourth is the exercise of the back of the tongue, the specific location of which is the groove behind the tongue. When practitioners can fully relax the jaw and stabilize the throat, they can make this open mouth exercise with the tongue sunken. It is mainly to reflect the respiratory status. Especially in the state of singing, it is the most critical part of the pharyngeal tone able to be perfectly embodied. Open mouth exercise with the tongue sunken can be fully controlled for about a month, but needs to be practiced every day.

\section{Conclusions}

Peking opera and opera are the treasure of Chinese and Western culture, able to span time and space and present art and praise the history in a similar form, which explains commonality and borderless of the art. From the aspect of vocal performing art, both reflect the particular pursuit of actors for shaping their own roles and creating artistry, and show the highest level people can reach in the music art. The re-emergence of two contemporary arts also demonstrates their excellent artistic skills and unique charm. We can say that male Dan in Peking opera and the castrato in opera are created by history accidentally, and the birth of them does not meet the conventional sense humanities can understand, but there is no doubt that the art value both left is never forgotten.

\section{Acknowledgments}

This paper is the phased result of Philosophy and Social Sciences Department "Twelfth Five-Plan"

Fund Project of Guangdong Province, "A comparative study of drama male Dan and castrato vocal music in Europe based on artistic phylogeny" (GD13XYS14)

\section{References}

[1] Li Mingdi. Vocal aesthetic characteristics of singing state of male Dan in Chinese opera. Journal of Henan Normal University (Philosophy and Social Sciences), 2009,36 (6): 265-266.

[2] Fang Hong. On "male Dan" art in China and western country from the booming phenomenon of Li Yugang, Vitas. Henan Normal University, 2013.22-25. 
[3] Zhao Muxi. Exploration on value of castrato and pharyngeal tone. Liaoning Normal University, 2012.25-29. 